\title{
The cue-dependent nature of state-dependent retrieval
}

\author{
JAMES ERIC EICH \\ University of Toronto, Toronto, Ontario MSS 7A7, Canada
}

\begin{abstract}
An enduring problem in the study of human state-dependent retrieval concerns the apparent unpredictability of the phenomenon. Although many investigators have observed that utilization of information in episodic memory critically depends for its success on restoration, at the time of attempted retrieval, of the pharmacological state in which the information was originally acquired, many others have been unable to find evidence of such state-dependent effects. Indeed, negative results are so common that human state dependence has come to be popularly regarded as an untrustworthy phenomenon of little practical or theoretical significance. The message of this article is that the unpredictability of state-dependent effects in man is more apparent than real. Evidence is presented to the effect that, with very few exceptions, failures to demonstrate state dependence are restricted to situations in which utilization of stored information is tested in the presence of discretely identifiable retrieval cues, and successes, to situations in which retrieval occurs in the absence of any observable reminders. It is also shown that when the conditions of retrieval, with respect to the presence or absence of explicit cues, remain constant, the probability of demonstrating state dependence also remains constant across a relatively broad spectrum of experimental conditions. Speculations about the nature of the cognitive mechanisms underlying the so-called "cuing effect" in human state dependence are offered, and promising new directions for research are outlined.
\end{abstract}

This article is concerned with the state-dependent retrieval (SDR) of information in human episodic memory (Tulving, 1972, 1976). The phenomenon of state dependence is defined by the outcomes of experiments that conform to the following basic design: A person is asked to memorize a list or collection of target items-common words, nonsense syllables, simple line drawings, or the like. The subject studies the list while in one of two pharmacological "states," drug intoxicated or sober, and is later tested for recall or recognition of the items either in the same state in which memorization occurred or in the alternate state. The finding of principal interest is that access to or retrieval of information about the target items is impaired when the subject's pharmacological state is changed between the study and test sessions of the experiment, in comparison with conditions in which his or her state remains the same on both occasions. This interaction of states at

This article is based on a dissertation submitted to the Department of Psychology at the University of Toronto in candidacy for the degree of Doctor of Philosophy. Insightful criticisms of the manuscript were offered by Fergus I. M. Craik, Janet A. Metcalfe, Bennet B. Murdock, Jr., and Endel Tulving. Preparation of the paper was facilitated by grants provided by the Regents of the University of California, the National Institute of Mental Health (through the offices of Richard C. Stillman and Richard J. Wyatt), and the National Research Council of Canada (Grant A8632, awarded to Professor Tulving). Requests for reprints should be forwarded to the author, who is now at the School of Social Sciences, University of California, Irvine, California 92717. study and at test defines the occurrence of statedependent retrieval. The phenomenon has been demonstrated with several psychoactive agents, including such commonly used, and often abused, drugs as alcohol, amphetamine, and barbiturate.

Human SDR has been a topic of experimental investigation for roughly a decade. Throughout this period, a problem of enduring concern has been the apparent unpredictability of the phenomenon. In a recent review of the literature, Eich (1977) noted that fewer than half of the experiments included in his survey produced reliable evidence of state dependence. Since it is likely that many experiments that failed to demonstrate SDR have never seen the light of day in print (cf. McNemar, 1960; Melton, 1962), this figure probably exaggerates the trustworthiness of the phenomenon. The problem of unpredictability becomes more acute in light of the fact that methodologically similar experiments have sometimes yielded dissimilar outcomes with respect to the occurrence of state dependence. For instance, in two recent studies of the state-dependent effects of alcohol on the multitrial free recall of abstract nouns, SDR was demonstrated in one (R.C. Petersen, 1977) but not in the other (Miller, Adesso, Fleming, Gino, \& Lauerman, 1978). Such discrepancies point to the conclusion that evidence of state-dependent retrieval in man "rests on precarious ground" (Hilgard \& Bower, 1975, p. 547) and may well represent a deterrent to research in a young field in which reliable effects are as likely as not to be found. 
The purpose of this article is to seek out and identify sources of the apparent unpredictability of statedependent effects in man. To this end, evidence will be examined bearing on several experimental variables that have been or might be suspected of playing key roles in the occurrence of the SDR phenomenon. Of the variables considered, one-the presence or absence of discretely identifiable retrieval cues in the cognitive environment of the rememberer-will be revealed to matter most. More precisely, it will be shown that, with very few exceptions, failures to demonstrate SDR are confined to conditions in which retrieval is tested in the presence of explicit reminders-category name cues, for example, or literal copies of the items or events to be rememberedand successes, to conditions in which testing takes place in the absence of "observable" cues. It will also be shown that when the conditions of retrieval, with respect to the presence or absence of explicit cues, are held constant, manipulations of other experimental variables, including the type of psychoactive drug administered and the nature of the target items, generally do not affect the likelihood of demonstrating state dependence. Thus, on the basis of the evidence and analyses described within, the inference is drawn that human statedependent retrieval is a cue-dependent phenomenon, that is, one whose occurrence critically depends on the nature of the retrieval cues that are available to the rememberer. In the terminal sections of the report, discussion centers on a possible explanation of the so-called "cuing effect" in human state dependence and also on implications of this effect that may be of interest to students of both memory in general and state-dependent retrieval in particular.

\section{SOURCES OF THE UNPREDICTABILITY OF STATE- DEPENDENT RETRIEVAL: THE CUING EFFECT}

\section{A Compendium of Experimental Studies \\ of State Dependence}

This part of the paper focuses on experimental evidence relevant to five factors that have been or might be thought to play important roles in the occurrence of state-dependent effects in man, specifically, (1) the type of psychoactive drug administered, (2) the dosage of drug dispensed, (3) the nature of the to-be-remembered items, (4) the "level" of item analysis, and (5) the nature of the retrieval cues available to the rememberer. Each of these variables will be considered in turn.

As a preliminary to further discussion, Table 1 presents a compendium of 27 experimental studies of human state dependence involving a total of 57 separately identifiable experimental conditions or cases-the basic unit of analysis in the table. The compendium originated through a comprehensive review of SDR experiments that were either published or presented at major conferences or symposia between January 1965 and December 1978. In surveying the literature, exclu- sive attention was paid to "cognitive" studies in which various symbols-abstract nouns, line drawings, nonsense syllables (CVCs), and the like-served as the target items. Studies of the state-dependent effects of drugs on autonomic responsivity (Crow \& Ball, 1975; Hinrichsen, Katahn, \& Levenson, 1974; Powell, Goodwin, Janes, \& Hoine, 1971), motor learning (Goodwin, Powell, Bremer, Hoine, \& Stern, 1969; Hinrichsen et al., 1974; Ley, Jain, Swinson, Eaves, Bradshaw, Kincey, Crowder, \& Abbiss, 1972; Roffman, Marshall, Silverstein, Karkalas, Smith, \& Lal, 1972), or operant discriminative avoidance (Goodwin et al., 1969; Hill, Schwin, Powell, \& Goodwin, 1973) were considered to be beyond the purview of the paper, and therefore, they were excluded from consideration. Also excluded were experiments involving the tasks of verbal interference (viz., A-C and A-B $B_{I}$ negative transfer; Tarter, 1970), "four-way picture choice" (Stillman, Weingartner, Wyatt, Gillin, \& Eich, 1974), learning of neologisms (Ley et al., 1972), serial anticipation (Ley et al., 1972; Storm, Caird, \& Korbin, Note 1), serial reconstruction (Hill et al., 1973; Stillman et al., 1974), and word association reproduction (Crow \& Ball, 1975; Goodwin et al., 1969; Hill et al., 1973; Weingartner \& Faillace, 1971). These six tasks have been used too infrequently (only one or two cases pertaining to each, except word association reproduction, which counts a total of four relevant cases) to allow accurate assessment of their sensitivity as instruments for detecting the occurrence of state dependence-a point to be taken up later in the paper (also see Footnote 8 ).

Further, the scope of the literature review was restricted to experiments in which normal adults participated as subjects, since these have contributed most of the available evidence on SDR. Studies of state dependence involving special groups of subjects-hyperactive children (Swanson \& Kinsbourne, 1976), for example, or individuals with histories of affective disturbance (Weingartner, Miller, \& Murphy, 1977)-will, however, be cited from time to time in the remainder of the article, as will experimental work with laboratory animals. Finally, most of the material appearing in the compendium comes from studies employing a 2 by 2 experimental design, in which two states at the time of acquisition of information about the target items (the study session) are crossed with these same two states at the time of attempted retrieval (the test session). One state is defined with respect to the administration of a particular dose of a psychoactive drug such as alcohol (the drug, or D, state), the other in reference to the administration of appropriate placebo material (the drug-free, or $\mathrm{N}$, state). The crossing of the two factors thus defines four unique experimental conditions: (1) study drug, test drug (DD), (2) study drug, test drug free (DN), (3) study drug free, test drug free (NN), and (4) study drug free, test drug (ND). Conditions $\mathrm{DD}$ and $\mathrm{NN}$ are designated congruent state conditions; DN and ND represent disparate state conditions. 
Given this design, the occurrence of SDR is signaled by a crossover between study and test states such that the level of test performance observed under congruent state conditions is reliably different from the level found under disparate state treatments. ${ }^{1}$ For present purposes, the phrase "different from" is tantamount to "higher than," since all of the experiments with which we will be concerned conform to so-called positivetransfer tasks or paradigms, that is, tasks such as free recall and recognition memory, in which the level of test performance may be assumed to be a monotonically increasing function of the accessibility of information in episodic memory about the items or events to be remembered (cf. Deese \& Hulse, 1967, p. 344). Thus, to the extent that a change of state between the study and test sessions of the experiment reduces the accessibility of relevant information stored in the episodic system, the level of test performance will be higher under congruent, as contrasted with disparate, state conditions.

Format of the compendium and types of retrieval cues. The 57 cases appearing in Table 1 are displayed in alphabetical order according to their source of reference. In addition to the reference information, every case is described in terms of the four following characteristics: (1) the psychoactive drug used to elicit state-dependent effects, (2) the nature of the to-be-remembered items or, where applicable, the composition of the cue-target pairs, (3) the outcome of the case with respect to the occurrence (or nonoccurrence) of SDR, ${ }^{2}$ and (4) the nature of the retrieval cues that are assumed to be available to the rememberer, a point considered in detail below.

In accord with ideas expressed by Tulving and his associates (e.g., Flexser \& Tulving, 1978; Tulving, 1976, 1979; Tulving \& Thomson, 1973), the assumption granted here is that remembering of an event always comes about as a consequence of an interaction between information stored in the past about that event (the memory trace) and information present in the immediate cognitive environment of the rememberer (the retrieval cue). Thus, remembering is thought to depend for its success on the degree to which retrieval information extracted from the cue matches or complements information contained in the target memory trace: the greater the compatibility between the two sources of information, the greater the effectiveness of the retrieval cue and the higher the probability of successful recollection (Flexser \& Tulving, 1978; Tulving, 1976).

One important implication of the idea of remembering as a joint product of information from two sourcesthe memory trace and the retrieval cue-is that different experimental tasks or paradigms may be distinguished on the basis of the exact nature of the retrieval information

Table 1

A Compendium of Experimental Studies of Human State-Dependent Retrieval

\begin{tabular}{|c|c|c|c|c|c|}
\hline Case & Reference & $\begin{array}{l}\text { Psychoactive } \\
\text { Drug }\end{array}$ & $\begin{array}{l}\text { Retrieval } \\
\text { Cues }\end{array}$ & $\begin{array}{c}\text { Target Items } \\
\text { (or Cue-Target Pairs) }\end{array}$ & SDR \\
\hline $\begin{array}{l}01 \\
02\end{array}$ & $\begin{array}{l}\text { Adam et al. (1974) } \\
\text { Adam et al. (1974) }\end{array}$ & $\begin{array}{l}\text { Isoflurane* } \\
\text { Isoflurane }\end{array}$ & $\begin{array}{l}\text { Copy } \\
\text { Copy }\end{array}$ & $\begin{array}{l}\text { Common Words } \\
\text { Common Words }\end{array}$ & + \\
\hline $\begin{array}{l}03 \\
04\end{array}$ & $\begin{array}{l}\text { Bustamante et al. (1968) } \\
\text { Bustamante et al. (1968) }\end{array}$ & $\begin{array}{l}\text { Amphetamine } \\
\text { Amytal }\end{array}$ & $\begin{array}{l}\text { Invisible } \\
\text { Invisible }\end{array}$ & $\begin{array}{l}\text { CVCs } \\
\text { CVCs }\end{array}$ & $\begin{array}{l}+ \\
+\end{array}$ \\
\hline $\begin{array}{l}05 \\
06\end{array}$ & $\begin{array}{l}\text { Bustamante et al. (1970) } \\
\text { Bustamante et al. (1970) }\end{array}$ & $\begin{array}{l}\text { Amphetamine } \\
\text { Amytal }\end{array}$ & $\begin{array}{l}\text { Invisible } \\
\text { Invisible }\end{array}$ & $\begin{array}{l}\text { Geometric Figures } \\
\text { Geometric Figures }\end{array}$ & + \\
\hline 07 & Cohen \& Rickles (1974) & Marijuana & List & CVCs/Common Words & - \\
\hline $\begin{array}{l}08 \\
09\end{array}$ & $\begin{array}{l}\text { Cowan }(1976) \\
\text { Cowan }(1976)\end{array}$ & $\begin{array}{l}\text { Alcohol } \\
\text { Alcohol }\end{array}$ & $\begin{array}{l}\text { Copy } \\
\text { Invisible }\end{array}$ & $\begin{array}{l}\text { Male Names } \\
\text { Male Names }\end{array}$ & $\dot{+}$ \\
\hline 10 & Crow \& Ball (1975) & Alcohol & Copy & Common Scenes & + \\
\hline $\begin{array}{l}11 \\
12\end{array}$ & $\begin{array}{l}\text { Darley et al. (1974) } \\
\text { Darley et al. (1974) }\end{array}$ & $\begin{array}{l}\text { Marijuana } \\
\text { Marijuana }\end{array}$ & $\begin{array}{l}\text { Copy } \\
\text { Invisible }\end{array}$ & $\begin{array}{l}\text { Common Words } \\
\text { Common Words }\end{array}$ & - \\
\hline $\begin{array}{l}13 \\
14 \\
15 \\
16\end{array}$ & $\begin{array}{l}\text { Eich (Note 2) } \\
\text { Eich (Note 2) } \\
\text { Eich (Note 2) } \\
\text { Eich (Note 2) }\end{array}$ & $\begin{array}{l}\text { Marijuana } \\
\text { Marijuana } \\
\text { Marijuana } \\
\text { Marijuana }\end{array}$ & $\begin{array}{l}\text { Copy } \\
\text { Invisible } \\
\text { Copy } \\
\text { Invisible }\end{array}$ & $\begin{array}{l}\text { "Deeply" Analyzed Words } \\
\text { "Deeply" Analyzed Words } \\
\text { "Shallowly" Analyzed Words } \\
\text { "Shallowly" Analyzed Words }\end{array}$ & $\begin{array}{l}- \\
+ \\
+\end{array}$ \\
\hline $\begin{array}{l}17 \\
18 \\
19 \\
20\end{array}$ & $\begin{array}{l}\text { Eich et al. (Note 3) } \\
\text { Eich et al. (Note 3) } \\
\text { Eich et al. (Note 3) } \\
\text { Eich et al. (Note 3) }\end{array}$ & $\begin{array}{l}\text { Marijuana } \\
\text { Marijuana } \\
\text { Marijuana } \\
\text { Marijuana }\end{array}$ & $\begin{array}{l}\text { Copy } \\
\text { Invisible } \\
\text { Copy } \\
\text { Invisible }\end{array}$ & $\begin{array}{l}\text { Common Words } \\
\text { Common Words } \\
\text { Rare Words } \\
\text { Rare Words }\end{array}$ & $\begin{array}{l}- \\
+ \\
+ \\
+\end{array}$ \\
\hline $\begin{array}{l}21 \\
22 \\
23 \\
24\end{array}$ & $\begin{array}{l}\text { Eich et al. (1975) } \\
\text { Eich et al. (1975) } \\
\text { Eich et al. (1975) } \\
\text { Eich et al. (1975) }\end{array}$ & $\begin{array}{l}\text { Marijuana } \\
\text { Marijuana } \\
\text { Marijuana } \\
\text { Marijuana }\end{array}$ & $\begin{array}{l}\text { Invisible } \\
\text { List } \\
\text { Invisible } \\
\text { List }\end{array}$ & $\begin{array}{l}\text { Common Category Exemplars } \\
\text { Category Names/Common Category Exemplars } \\
\text { Rare Category Exemplars } \\
\text { Category Names/Rare Category Exemplars }\end{array}$ & $\begin{array}{l}+ \\
- \\
+ \\
-\end{array}$ \\
\hline 25 & Goodwin et al. (1969) & Alcohol & Copy & "Emotional" Pictures & - \\
\hline
\end{tabular}


Table 1 Continued

\begin{tabular}{|c|c|c|c|c|c|}
\hline Case & Reference & $\begin{array}{l}\text { Psychoactive } \\
\text { Drug }\end{array}$ & $\begin{array}{c}\text { Retrieval } \\
\text { Cues }\end{array}$ & $\begin{array}{c}\text { Target Items } \\
\text { (or Cue-Target Pairs) }\end{array}$ & SDR \\
\hline $\begin{array}{l}26 \\
27\end{array}$ & $\begin{array}{l}\text { Goodwin et al. (1969) } \\
\text { Goodwin et al. (1969) }\end{array}$ & $\begin{array}{l}\text { Alcohol } \\
\text { Alcohol }\end{array}$ & $\begin{array}{l}\text { Copy } \\
\text { Invisible }\end{array}$ & $\begin{array}{l}\text { "Neutral" Pictures } \\
\text { Word Strings }\end{array}$ & + \\
\hline $\begin{array}{l}28 \\
29\end{array}$ & $\begin{array}{l}\text { Hill et al. (1973) } \\
\text { Hill et al. (1973) }\end{array}$ & $\begin{array}{l}\text { Marijuana } \\
\text { Marijuana }\end{array}$ & $\begin{array}{l}\text { Invisible } \\
\text { Invisible }\end{array}$ & $\begin{array}{l}\text { Meaningful or Syntactic Sentences } \\
\text { Random Word Strings }\end{array}$ & $\overline{+}$ \\
\hline 30 & Hurst et al. (1969) & Amphetamine & List & Unrelated Word Pairs & - \\
\hline 31 & Ley et al. (1972) & Amytal & List & CVC Pairs & - \\
\hline 32 & Miller et al. (1978) & Alcohol & Invisible & Abstract Nouns & - \\
\hline $\begin{array}{l}33 \\
34\end{array}$ & $\begin{array}{l}\text { Osborn et al. (1967) } \\
\text { Osborn et al. (1967) }\end{array}$ & $\begin{array}{l}\text { Pentothal } \\
\text { Pentothal }\end{array}$ & $\begin{array}{l}\text { Copy } \\
\text { List }\end{array}$ & $\begin{array}{l}\text { Simple Line Drawings } \\
\text { Letters/Words }\end{array}$ & - \\
\hline $\begin{array}{l}35 \\
36 \\
37 \\
38\end{array}$ & $\begin{array}{l}\text { Parker et al. (1976) } \\
\text { Parker et al. (1976) } \\
\text { Parker et al. (1976) } \\
\text { Parker et al. (1976) }\end{array}$ & $\begin{array}{l}\text { Alcohol* } \\
\text { Alcohol** } \\
\text { Alcohol* } \\
\text { Alcohol** }\end{array}$ & $\begin{array}{l}\text { Copy } \\
\text { Copy } \\
\text { List } \\
\text { List }\end{array}$ & $\begin{array}{l}\text { Common Scenes } \\
\text { Common Scenes } \\
\text { Letters/Months of the Year } \\
\text { Letters/Months of the Year }\end{array}$ & $\begin{array}{l}- \\
- \\
-\end{array}$ \\
\hline $\begin{array}{l}39 \\
40 \\
41 \\
42 \\
43\end{array}$ & $\begin{array}{l}\text { Petersen }(1977) \\
\text { Petersen (1977) } \\
\text { Petersen (1977) } \\
\text { Petersen (1977) } \\
\text { Petersen (1977) }\end{array}$ & $\begin{array}{l}\text { Alcohol } \\
\text { Alcohol } \\
\text { Alcohol } \\
\text { Alcohol } \\
\text { Alcohol }\end{array}$ & $\begin{array}{l}\text { Invisible } \\
\text { Invisible } \\
\text { Invisible } \\
\text { List } \\
\text { List }\end{array}$ & $\begin{array}{l}\text { Abstract Nouns } \\
\text { Concrete Nouns } \\
\text { Common Category Exemplars } \\
\text { Category Names/Common Category Exemplars } \\
\text { "Image" Cues/"Image" Exemplars }\end{array}$ & $\begin{array}{l}+ \\
+ \\
+ \\
- \\
-\end{array}$ \\
\hline 44 & Rickles et al. (1973) & Marijuana & List & CVCs/Common Words & + \\
\hline $\begin{array}{l}45 \\
46\end{array}$ & $\begin{array}{l}\text { Roffman et al. (1972) } \\
\text { Roffman et al. (1972) }\end{array}$ & $\begin{array}{l}\text { Amphetamine } \\
\text { Amphetamine }\end{array}$ & $\begin{array}{l}\text { List } \\
\text { List }\end{array}$ & $\begin{array}{l}\text { CVCs/"Neutral" Words } \\
\text { CVCs/"Pleasant"" Words }\end{array}$ & - \\
\hline $\begin{array}{l}47 \\
48\end{array}$ & $\begin{array}{l}\text { Stillman et al. (1974) } \\
\text { Tarter (1970) }\end{array}$ & $\begin{array}{l}\text { Marijuana } \\
\text { Alcohol }\end{array}$ & $\begin{array}{l}\text { Invisible } \\
\text { List }\end{array}$ & $\begin{array}{l}\text { Common Words } \\
\text { CVCs/Common Words }\end{array}$ & - \\
\hline $\begin{array}{l}49 \\
50 \\
51 \\
52\end{array}$ & $\begin{array}{l}\text { Weingartner (1978) } \\
\text { Weingartner (1978) } \\
\text { Weingartner (1978) } \\
\text { Weingartner (1978) }\end{array}$ & $\begin{array}{l}\text { Eserine } \\
\text { Eserine } \\
\text { Eserine } \\
\text { Eserine }\end{array}$ & $\begin{array}{l}\text { Invisible } \\
\text { List } \\
\text { Invisible } \\
\text { List }\end{array}$ & $\begin{array}{l}\text { Common Category Exemplars } \\
\text { Category Names/Common Category Exemplars } \\
\text { Rare Category Exemplars } \\
\text { Category Names/Rare Category Exemplars }\end{array}$ & $\begin{array}{l}+ \\
- \\
+ \\
-\end{array}$ \\
\hline 53 & Weingartner \& Faillace (1971) & Alcohol & Invisible & Common Words & + \\
\hline 54 & Weingartner et al. (1973) & Alcohol & Invisible & Verbal Free Associations & + \\
\hline $\begin{array}{l}55 \\
56\end{array}$ & $\begin{array}{l}\text { Weingartner et al. (1976) } \\
\text { Weingartner et al. (1976) }\end{array}$ & $\begin{array}{l}\text { Alcohol } \\
\text { Alcohol }\end{array}$ & $\begin{array}{l}\text { Invisible } \\
\text { Invisible }\end{array}$ & $\begin{array}{l}\text { Abstract Nouns } \\
\text { Concrete Nouns }\end{array}$ & + \\
\hline 57 & Wickelgren (1975) & Alcohol & Copy & Common Words & - \\
\hline
\end{tabular}

Note-Cases in which evidence of SDR did and did not obtain are designated + and -, respectively.

*Low drug dosages. "High drug dosages.

or cues available to the rememberer. In recognition, for example, information that may facilitate the retrieval of information stored in episodic memory is explicitly presented to the rememberer in the form of copy cues: literal replicas of the items or events to be remembered (Tulving, 1976; also see Adam, Castro, \& Clark, 1974, Cases 01 and 02 in Table 1; Cowan, 1976, Case 08; Crow \& Ball, 1975, Case 10; Darley, Tinklenberg, Roth, \& Atkinson, 1974, Case 11; Goodwin et al., 1969, Cases 25 and 26; Osborn, Bunker, Cooper, Frank, \& Hilgard, 1967, Case 33; Parker, Birnbaum, \& Noble, 1976, Cases 35 and 36; Wickelgren, 1975, Case 57; Eich, Note 2, Cases 13 and 15; Eich, Stillman, Weingartner, Wyatt, \& Beardsley, Note 3, Cases 17 and 19).

Alternatively, in cued recall situations, specifically, the tasks of category cuing (Eich, Weingartner, Stillman, \& Gillin, 1975, Cases 22 and 24; R. C. Petersen, 1977,
Cases 42 and 43; Weingartner, 1978, Cases 50 and 52) and paired associate learning (Cohen \& Rickles, 1974, Case 07; Hurst, Radlow, Chubb, \& Bagley, 1969, Case 30; Ley et al., 1972, Case 31; Osborn et al., 1967, Case 34; Parker et al., 1976, Cases 37 and 38; Rickles, Cohen, Whitaker, \& McIntyre, 1973, Case 44; Roffman et al., 1972, Cases 45 and 46; Tarter, 1970, Case 48), retrieval information is explicitly provided in the guise of list cues: units of information, other than copy cues, that originally appeared as part of the experimental list (cf. Tulving \& Thomson, 1973).

Finally, in situations in which retrieval is tested in the absence of explicit list or copy cues, specifically, the tasks of free recall (Bustamante, Jordán, Vila, González, \& Insua, 1970, Cases 05 and 06; Bustamante, Rosselló, Jordán, Pradere, \& Insua, 1968, Cases 03 and 04; Darley et al., 1974, Case 12; Miller et al., 1978, Experiment 2, Case 32; R. C. Petersen, 1977, Cases 3941; Weingartner, 
1978, Cases 49 and 51; Weingartner, Adefris, Eich, \& Murphy, 1976, Cases 55 and 56; Weingartner \& Faillace, 1971, Experiment 2, Case 53; Eich, Note 2, Cases 14 and 16; Eich et al., Note 3, Cases 18 and 20) and nominally noncued serial recall (Goodwin et al., 1969, Case 27; Hill et al., 1973, Cases 28 and 29; Stillman et al., 1974, Case 47; Weingartner, Eich, \& Allen, 1973, Case 54), it is convenient to assume that information necessary for retrieval is carried by invisible cues: cues whose presence cannot be directly perceived by the experimenter, nor, perhaps, by the rememberer either (cf. Tulving \& Watkins, 1975). Although invisible cues are assumed to guide retrieval under conditions of nominally noncued free or serial recall, it is entirely possible that they may also be responsible for instances of remembering that occur in the presence of discretely identifiable list or copy cues. As pointed out by Tulving and Thomson (1973), subjects may retrieve items by means of cues other than those explicitly provided by the experimenter and match the items to the explicit cues after retrieval has taken place. Such cases will tend to inflate and distort any absolute measures of cue effectiveness, and it is for this reason that the potency of list and copy cues is sometimes assessed in relation to the basic reference level of recall obtained in the absence of "observable" reminders.

\section{Sources of Unpredictability}

Earlier, it was remarked that human state-dependent retrieval has acquired a reputation as an unpredictable phenomenon. In light of the outcomes of the experiments summarized in Table 1, this reputation is apparently well deserved. Inspection of the compendium reveals that evidence of SDR was obtained in 26 of the 57 experimental cases, a rather unimpressive value of about $46 \%$. On further inspection it also becomes apparent that the methods of the cases differ in several respects, as in, for instance, the type of psychoactive drug administered or the nature of the to-be-remembered items. Although these differences complicate the comparison of findings obtained in one experiment with those obtained in another, it still may be possible to identify one or more sources of the manifest unpredictability of human state dependence. Several of the more likely of these "sources" are considered below.

Type of psychoactive drug. As is indicated in Table 1, seven psychoactive agents-alcohol, amphetamine, amytal (a short-acting barbiturate), eserine (a cholinesterase inhibitor), isoflurane (a general anesthetic), marijuana, and pentothal (an ultrashort-acting barbiturate)-have been tested for their capacity to produce state-dependent effects in normal human adults. ${ }^{3}$ These seven drugs represent four broadly defined classes or types of psychoactive agent: anesthetic (alcohol, amytal, isoflurane, and pentothal), anticholinesterase (eserine), cannabinoid (marijuana), and stimulant (amphetamine). Since these drug types are known to vary widely in both their psychopharmacologic and their pharmacokinetic properties (see Goodman \& Gilman, 1975), it would not come as too great a surprise to find that they also vary in their effectiveness as agents of state dependence.

Data concerning the role of type of psychoactive drug in the occurrence of SDR appear in Table 2. Although the data are tabled in a format appropriate for analysis by chi square, the small numbers of cases pertaining to the anticholinesterase and stimulant classes precludes the use of this method of analysis (Hays, 1973). In lieu of chi square, six Fisher exactprobability tests (Siegel, 1956) were performed, one for every pairwise combination of drug types. None of these tests approached statistical significance, which suggest that the occurrence of state-dependent effects in man is not conditional on the administration of a certain type or types of psychoactive agent.

The emphasis on "psychoactive" is noteworthy. Results obtained in many experiments converge on the conclusion that drugs that exclusively act outside the central nervous system (i.e., nonpsychoactive agents) do not produce state dependence in laboratory animals. The original evidence for this conclusion came from an elegant series of experiments carried out by Overton (1964, 1966). Using rats as subjects, Overton showed that the state-dependent effects of pentobarbital (Nembutal), a centrally acting anesthetic, were not mediated by sensory cues provided by the drug; his efforts to mimic the effects of state change using selected interoceptive and exteroceptive stimuli were repeatedly unsuccessful. Several more recent studies lend additional credibility to the idea that state dependence in animals critically depends for its occurrence on the direct action of a drug on the brain, and not simply on the evocation

Table 2

Case Outcome as a Function of the Type of Psychoactive Drug Administered

\begin{tabular}{|c|c|c|c|c|}
\hline \multirow[b]{2}{*}{ Type of Drug } & \multicolumn{2}{|c|}{ Case Outcome } & \multicolumn{2}{|c|}{ Cases } \\
\hline & + & - & + & - \\
\hline Anesthetic & 13 & 16 & $02,04,06,09,10,27,39-41,53-56$ & $01,08,25,26,31-38,42,43,48,57$ \\
\hline Anticholinesterase & 2 & 2 & 49,51 & 50,52 \\
\hline Cannabinoid & 9 & 10 & $12,14,16,18,20,21,23,29,44$ & $07,11,13,15,17,19,22,24,28,47$ \\
\hline Stimulant & 2 & 3 & 03,05 & $30,45,46$ \\
\hline
\end{tabular}

Note-Entries in the columns marked + and - are the number of cases in which evidence of SDR did and did not obtain, respectively. "Cases" refers to entries in Table l. Drug types are described in the text. 
of a mélange of peripheral drug effects (e.g., Downey, 1975; Overton, 1971, 1973).

The role of central vs. peripheral effects of drugs in the occurrence of human state dependence is unclear at present. All studies of human SDR reported to date have invoived the administration of centrally acting drugs, and in most instances the agents were given in doses sufficient to produce extensive effects on both the central and peripheral nervous systems (see Eich, 1977). In the absence of any "hard" evidence relevant to the issue at hand, it is logical to assume that in both man and animal, the occurrence of state dependence is contingent on the administration of centrally acting drugs. However, within the realm of psychoactive agents, it does not seem to matter very much whether the drug used to produce SDR in man is an anesthetic such as amytal or a stimulant such as amphetamine, or whether the sensory cues provided by the drug are typically robust and readily discriminable, as is true of alcohol, or relatively insignificant, as is the case with eserine (Overton, 1972): All are equally effective, or ineffective, in eliciting state-dependent effects. Thus it is apparent that the unpredictability of human state-dependent retrieval cannot be plausibly ascribed to the administration of ineffective types of psychoactive drug.

Dosage of psychoactive drug. Granted that the likelihood of demonstrating human state dependence is uncorrelated with the type of centrally acting agent administered, it nevertheless is conceivable that the phenomenon may critically depend for its occurrence on the administration of specific quantities of drug. In laboratory animals, the magnitude of state-dependent effects has been found to be directly proportional to drug dosage across a wide variety of subject species, experimental tasks, and, with the possible exception of antimuscarinics such as scopolamine, drug types (Overton, 1971, 1972). In man, however, the nature of the relation between size of state-dependent effects and drug dosage is much less clear. What little evidence there is suggests that human SDR is most readily demonstrated using moderate amounts of the drugs named earlier (Overton, 1972). High dosages of many centrally acting drugs, especially anesthetics, often produce severe retention deficits that conceivably may obscure any state-dependent effects that might be present. Indeed,
Overton (1972) has speculated that excessive dosing may have been responsible for the negative results that were obtained in an early study of SDR reported by Osborn et al. (1967, Cases 33 and 34), whose subjects were heavily sedated with pentothal. On the other hand, evidence culled from a large number of experiments indicates that "interactive" or state-dependent effects almost always occur in conjunction with a reliable "main" effect of drug on the acquisition of information about the items or events to be remembered, the retention of that information, or both acquisition and reten. tion (see Eich, 1977; Swanson \& Kinsbourne, 1976). Such main effects may be facilitative or inhibitory in nature and may be manifested in many ways, depending upon the particulars of the experimental task at hand (see, for instance, Parker et al., 1976; Roffman et al., 1972). If we assume, for the moment, that the presence of a reliable effect of drug on either or both acquisition and retention is a necessary condition for the demonstration of human SDR, and given that such main effects are unlikely to obtain when relatively small quantities of drug are dispensed (Eich, 1977), we may infer that dosages too low to elicit a reliable main effect will also be too low to elicit state dependence. Thus, it may be that failures to demonstrate state-dependent effects in man are attributable to the administration of "ineffective" drug doses, that is, quantities of psychoactive agent that are not sufficient to produce reliable acquisition-retention effects.

Evidence relevant to the role of drug-produced main effects in the occurrence of human SDR is illustrated in Table 3. Of the 57 cases appearing in the compendium of SDR experiments (Table 1), all but 6 (Cases 08, $09,11,12,28$, and 29) may be classified according to the presence or absence of a reliable main effect of drug on either or both acquisition and retention. (Too few data are provided in the reports of the six missing cases to permit unequivocal determination of the presence or absence of main effects.) Each main effect present and main effect absent case may in turn be classified according to its outcome with respect to the occurrence of state dependence, as shown in Table 3.

Looking first at cases in which SDR was found, it can be seen that in all 23 such cases a reliable effect of drug on either acquisition or retention also obtained.

Table 3

Case Outcome as a Function of the Presence or Absence of a Main Effect of Psychoactive Drug on Acquisition or Retention

\begin{tabular}{ccccc}
\hline \multirow{2}{*}{$\begin{array}{c}\text { Main } \\
\text { Effect }\end{array}$} & \multicolumn{2}{c}{ Case Outcome } & & \multicolumn{2}{c}{ Cases } \\
\cline { 2 - 5 } \cline { 4 - 5 } & + & - & & \multicolumn{1}{c}{+} \\
Present & 23 & 21 & $02-06,10,14,16,18,20,21,23$, & $13,15,17,19,22,24,25,30$, \\
Absent & 0 & 7 & $27,39-41,44,49,51,53-56$ & $32-36,38,45-48,50,52,57$ \\
& & & & $01,07,26,31,37,42,43$ \\
\hline
\end{tabular}

Note-Entries in the columns marked + and - are the numbers of cases in which evidence of SDR did and did not obtain, respectively. "Cases" refers to entries in Table 1. 
This observation thus squares with earlier reports (e.g., Eich, 1977; Swanson \& Kinsbourne, 1976) that the demonstration of drug-produced main effects is a necessary condition for the demonstration of interactive or state-dependent effects.

That the presence of a main effect of drug on either acquisition or retention does not represent a sufficient condition for the occurrence of state-dependent retrieval is apparent upon inspection of cases in which the phenomenon was not observed. As shown in Table 3, there are 21 cases in which evidence of SDR failed to materialize despite the presence of reliable acquisition-retention effects. Plainly, some factor or factors in addition to the presence of drug-produced main effects must be responsible for the occurrence of SDR. As also is shown in Table 3, there are seven cases in which neither a main effect nor a state-dependent effect of drug was found. Since it appears that the presence of a main effect of drug is a necessary, albeit insufficient, condition for the demonstration of state dependence, the negative outcomes obtained in Cases 01, 07, 26, 31, 37, 42, and 43 of Table 1 may be ascribed to the administration of centrally acting drugs in doses that produced negligible main effects. However, given that these seven negative results represent only about $23 \%$ of the failures to demonstrate SDR that are stipulated in the compendium, it is clear that the search for sources of the unpredictability of human state dependence must progress beyond recognition of the part that drug dosage, as measured by the presence or absence of reliable main effects, plays in the occurrence of the phenomenon.

At the close of the preceding subsection, it was claimed that the probability of demonstrating statedependent effects in man is independent of the type of centrally acting agent administered. The reader will recall that this conclusion emerged from an analysis of the outcomes of all 57 cases that appear in the compendium of SDR experiments. Now we have seen that in seven specific instances, the dose of drug dispensed was probably too low to elicit state dependence, and the question naturally arises as to the manner in which these seven negative outcomes are distributed among the various kinds of drugs. It is conceivable, for example, that all seven cases of ineffective dosing may be confined to experiments concerned with the state-dependent properties of marijuana. If so, then of the 10 failures to demonstrate marijuana (or cannabinoid) -produced SDR that are cited in Table 2, only 3 could not be attributed to the administration of ineffective drug doses. Given that there are nine cases in which state dependence was observed using marijuana (Table 2), the percentage of positive-outcome cases, conditionalized on effective dosing, would be $75 \%$ $(9 / 12)$. This figure is considerably higher than the corresponding "unconditionalized" value of 47\% (9/19) and thus would cast doubt on the veracity of the claim that state-dependent effects are no more likely to occur with marijuana than with any other psychoactive agent.

The actual data do not bear out this possibility. Of the seven instances of ineffective dosing, only one (Case 07) pertains to the administration of marijuana. This is very close to the number of cases that we would expect to find if the instances of ineffective dosing were distributed at random among the four classes of drugs specified in Table $2{ }^{4}$ The remaining six instances of ineffective dosing (Cases 01, 26, 31, 37, 42, and 43) relate to studies of SDR involving anesthetics, and Kolmogorov-Smirnov analysis (Siegel, 1956) reveals that this observed value does not depart significantly from the number of cases expected by chance (see Footnote 4 ). Thus, the conclusion drawn earlier still stands: Statedependent effects are no more or less likely to obtain with marijuana than with anesthetics, stimulants, or cholinesterase inhibitors.

Nature of the target items and the "level" of item analysis. Yet a third possible source of the unpredictability of human state-dependent retrieval concerns the nature of the stimulus events whose occurrence the subject is asked to remember. As indicated in Table 1 , several kinds of items-common words, meaningful sentences, and pictures of familiar scenes, to name just three-have served as the foci of to-be-remembered events in experimental studies of SDR. Granted that how well something is remembered depends in part on what that something is (Tulving \& Thomson, 1973), it is conceivable that the nature of the target items may play an integral role in the occurrence of state dependence.

Evidence presented in the compendium of SDR studies lends little support to this conjecture. Careful reading of the compendium reveals that state-dependent retrieval has been found to occur with roughly a dozen different types of target items, including geometric figures (Case 05), uncommon category exemplars (Case 23), free associations to words (Case 54), and both abstract and concrete nouns (Cases 55 and 56). Given this diversity of stimulus materials, it would seem that, in the main, the demonstration of state-dependent effects is not conditional on the use of a particular type or types of to-be-remembered item.

Of related interest is the possibility that the occurrence of SDR may critically depend on the nature of the encoding operations the subject performs on the target items at the time of their original presentation. Recent experiments by Craik and his colleagues (e.g., Craik \& Tulving, 1975; Fisher \& Craik, 1977; Moscovitch \& Craik, 1976) have shown that the memorability of one and the same target word may vary enormously depending on the "level" at which the word is analyzed or encoded at input, with "deep," semantically oriented analysis typically producing both better recall and better recognition performance than "shallow," nonsemantic encoding. In light of the findings of these 
experiments, the question arises whether-and, if so, how-the occurrence of state dependence is related to the level at which the to-be-remembered items are analyzed at input.

As of this writing, only one study of SDR from the perspective afforded by the levels-of-analysis framework has been reported, this being an investigation of the statedependent properties of marijuana performed by Eich (Note 2, Cases 13-16). During the study phase of this experiment, every participant (male college students) was presented 24 common words, half of which he analyzed at a deep level and half at a shallow level. Deep analysis was encouraged by asking the subject either to produce a synonym for a particular target word or to rate the word's "pleasantness" on a 7-point scale. Shallow analysis, in contrast, was fostered by instructing the subject either to generate a rhyme for a given target word or to define the word's part of speech (see Hyde \& Jenkins, 1969). To ensure against itemselection artifacts, each of the 24 target words was included in each of the four analytical tasks (synonym production, pleasantness rating, rhyme generation, and part-of-speech definition) equally often across subjects.

Following a 4-h retention interval, the subject was asked to recall as many of the target words as possible in any order. Immediately upon completion of free recall, the subject was given a test of recognition memory using two-alternative forced-choice techniques. (In point of fact, only 12 of the 20 subjects in the study were tested for recognition; the remaining 8 subjects were engaged in a different experiment immediately following free recall and therefore had to forego the recognition test.) Both free recall and recognition memory were "surprise" tests inasmuch as the subject had not been led to expect that his powers of recollection would be examined. Every participant in the experiment studied the target words shortly after having smoked a marijuana cigarette containing $15 \mathrm{mg}$ of delta-9-tetrahydrocannabinol (THC), the presumed active ingredient in marijuana or the immediate precursor thereof (see Eich et al., 1975; Stillman et al., 1974). Ten subjects were subsequently tested for both free recall and recognition memory while in a comparable state of marijuana intoxication (the congruent state, Condition DD); an equal number of subjects were tested while sober (the disparate state, Condition DN).

The results of the free recall test, in the form of mean proportions of target words produced, are illustrated in Figure 1. Inspection of the figure reveals that regardless of experimental condition [i.e., congruent (DD) vs. disparate (DN) states], deep analysis yielded better recall than did shallow, a typical "levels" effect $[\mathrm{F}(1,18)=10.48, \mathrm{MSe}=.017]$. It may also be seen that, irrespective of the level of word analysis, a greater proportion of words was recalled under congruent as opposed to disparate states, a typical SDR effect $[\mathrm{F}(1,18)=8.61, \mathrm{MSe}=.021] .^{5}$ Finally, and, from the

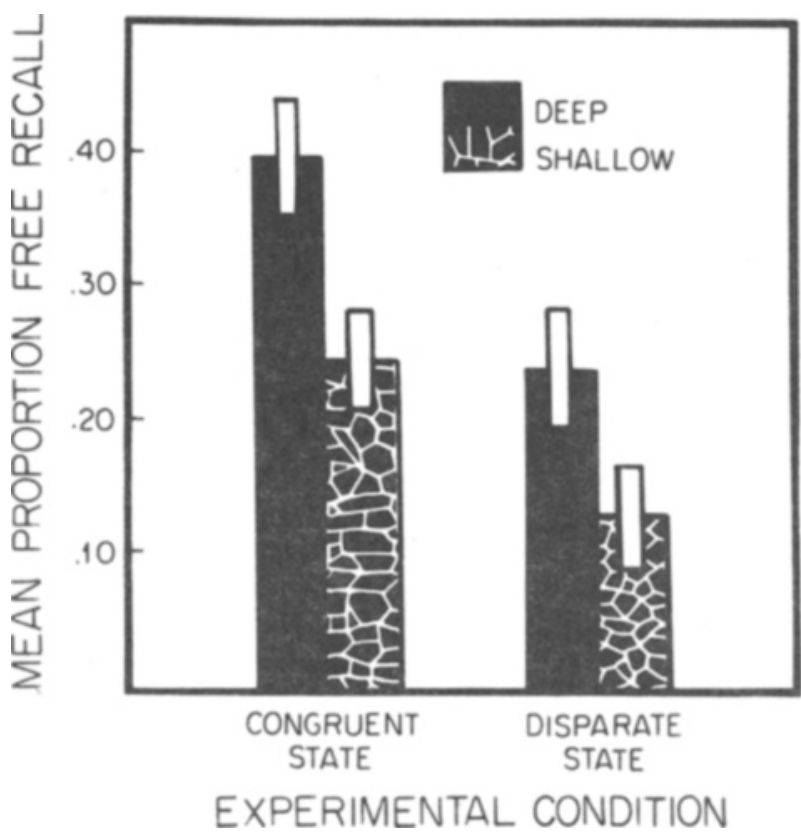

Figure 1. Mean proportions (and corresponding standard errors) of words produced in free recall as functions of experimental condition (congruent vs. disparate state) and "level" of word analysis (deep vs. shallow).

perspective of the present discussion, most important, it is apparent that the magnitude of the difference in word recall found between congruent and disparate states was not appreciably affected by the level at which the words were analyzed at input $(F<1.00)$. This finding, viewed within the context of remarks made earlier in this subsection, suggests that the occurrence of state-dependent retrieval is independent not solely of what it is that the subject is asked to remember, but of how it is analyzed or encoded as well.

Earlier, it was stated that participants in the levels-ofanalysis study of SDR were tested for recognition as well as for free recall of the target words. Results of the recognition test were similar to those obtained in free recall with respect to the demonstration of a characteristic, although attenuated, levels effect; the mean proportions of deeply and shallowly analyzed words correctly identified were .88 and .79 , respectively $[\mathrm{F}(1,10)=3.77, \mathrm{MSe}=.013, .050<\mathrm{p}<.100]$. However, in sharp contrast to the outcome of the free recall test, experimental manipulation of the similarity between study and test states produced negligible effects on the accuracy of recognition memory: Whereas an average of .89 and .78 of the deeply and shallowly analyzed words were recognized under Condition DD, the corresponding means generated under Condition DN were .88 and .81 (the $F$ ratios for the main effect of experimental condition and the interaction of experimental condition with level of word analysis were both less than unity). ${ }^{6}$ The finding that evidence of state- 
dependent retrieval obtains under conditions of free recall but not recognition memory suggests that the occurrence of the phenomenon may be contingent on the use of certain kinds of experimental tasks or paradigms. What it is that determines the sensitivity of a given task to the detection of state-dependent effects is a question of obvious import, and one that will soon be examined in fine detail.

Summary. We have seen that the unpredictability of human state-dependent retrieval is not directly linked to the type of psychoactive drug that is used to produce the phenomenon, the nature of the items whose occurrence the subject is asked to remember, or the "level" at which the items are analyzed at input. It has also been observed that in seven specific instances (viz., Cases 01 , $07,26,31,37,42$, and 43 of Table 1), failures to demonstrate state dependence probably resulted from the administration of ineffective drug doses (see the section titled "Dosage of psychoactive drug"). Since the pool of negative outcomes numbers 31 , this means that approximately $77 \%$ of the failures to demonstrate SDR that appear in Table 1 cannot be explained on the basis of drug type, drug dosage, composition of the to-be-remembered items, or level of item analysis.

Fortunately, the unpredictability of human state dependence is not quite as intractable as the preceding remarks would seem to suggest. There exists another experimental variable whose manipulation accounts for most of the remaining variance in case outcome with respect to the occurrence of SDR. This variable is the presence or absence of discretely identifiable retrieval cues in the cognitive environment of the rememberer, and the part "observable" cues play in the occurrence of human state dependence is the focal point of discussion in the next section of the paper.

\section{The Cuing Effect in State-Dependent Retrieval}

We begin with the observation that remembering of an event never occurs "spontaneously": Retrieval is always effected by a stimulus, a query, or a cue whose informational content, its "interpretation by the system in semantic memory" (Tulving \& Watkins, 1975, p. 274), matches or complements information stored in episodic memory about the event. Thus, remembering is regarded as a joint product of trace information acquired in the past and appropriate retrieval information present in the immediate cognitive environment of the rememberer (Flexser \& Tulving, 1978; Tulving, 1976).

In certain experimental tasks, such as free recall, remembering occurs in the absence of any specific instigators; nevertheless, it is plausible to assume that invisible cues carry the retrieval information necessary to bring about remembering (Tulving \& Bower, 1974; Tulving \& Watkins, 1975). In other tasks, such as paired associate learning, information that may be useful in retrieval is provided in the form of discretely identifiable list cues, as when, for example, the stimulus member of a previously studied word pair is presented as a cue for the recovery of the response member of the pair. And in tasks involving recognition rather than recall, retrieval information is conveyed by special kinds of list cues-copy cues, or literal replicas of the items or events to be remembered (Tulving, 1976; Tulving \& Thomson, 1973). In the remainder of this section, evidence bearing on the roles of invisible, list, and copy cues in the occurrence of state-dependent retrieval will be examined.

The first piece of relevant evidence comes from a study of the state-dependent properties of marijuana reported by Eich et al. (1975, Cases 21-24; also see Eich, 1977). In this experiment, each of 15 male college students alternately studied and was tested for the recall of a long list of words under the four conditions $\mathrm{DD}, \mathrm{DN}, \mathrm{ND}$, and $\mathrm{NN}$, where $\mathrm{D}$ and $\mathrm{N}$ designate the states induced by smoking a marijuana cigarette containing 10 and, effectively, $0 \mathrm{mg}$ THC, respectively.

During the study phase of every condition, the subject was asked to memorize a list composed of 12 categories of conceptually related words, each category consisting of a category name (e.g., Flowers) and four exemplars of the category, two common (e.g., DAISY, ROSE) and two rare (e.g., JONQUIL, ZINNIA). (The distinction between common and rare category exemplars was based on normative data published by Battig and Montague, 1969.) Four equivalent lists were constructed, one for each condition. Lists were read once in a blocked fashion at a rate of approximately $1.5 \mathrm{sec}$ per category name or category exemplar. The subject was informed, immediately prior to list presentation, that he would be asked to recall the 48 exemplars included in the list following a 4-h delay. The interval separating successive conditions ranged from 2 to 3 days, and the order in which the subjects completed the four conditions was systematically varied.

During the test phase of every condition, the subject was given two tests of exemplar recall. In both tests his mission was to reproduce, in any preferred order, as many as possible of the exemplars that had been studied earlier that day. Further, both tests required written responses and were self-paced. The critical difference between the two examinations was that, in the test of category cuing, the subject was provided a listing of the 12 appropriate category names as an aid in reproducing the exemplars, whereas in the test of free recall, the subject was not explicitly reminded of the category names and hence was left to his own devices to generate the "invisible" cues necessary for retrieval. The test of category cuing was always administered immediately upon completion of free recall.

Data gleaned from the experiment were submitted to a four-factor analysis of variance with study state, test state, exemplar type, and test type treated as withinsubjects variables. The analysis revealed that the simple effects of study state [study $N$ superior to study $D$ : 
$\mathrm{F}(1,14)=5.00, \mathrm{MSe}=.022]$, exemplar type [common superior to rare: $F(1,14)=23.27$, MSe $=.011]$, and test type [category cuing superior to free recall: $F(1,14)=$ $116.90, \mathrm{MSe}=.022$ ] were statistically reliable; so too was the interaction of exemplar type with test type $[\mathrm{F}(1,14)=24.88, \mathrm{MSe}=.008] \quad$ (cf. Bahrick, 1971; Wood, 1967).

Also reliable, and of more immediate interest, was the triple interaction among study state, test state, and test type $[\mathrm{F}(1,14)=7.27, \mathrm{MSe}=.012]$. The locus of this interaction may be identified in Figure 2 , in which the mean proportions of category exemplars recalled are depicted as functions of exemplar type, test type, and experimental condition (i.e., congruent state, the average level of recall obtained under Conditions DD and NN, and disparate state, the average yielded by Conditions DN and ND). Inspection of the figure reveals that,

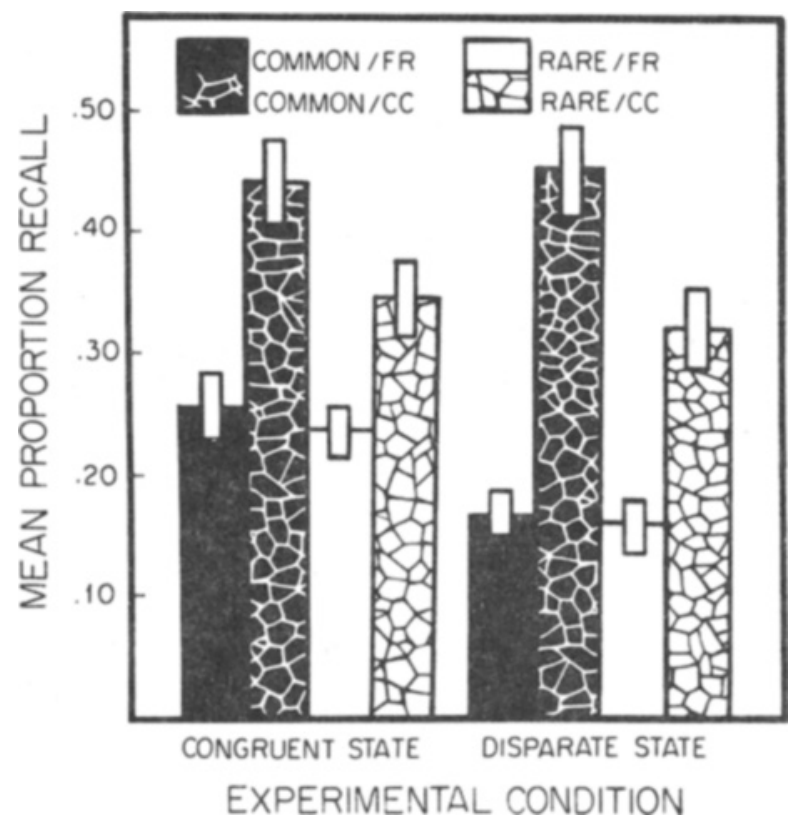

Figure 2. Mean proportions (and corresponding standard errors) of exemplars recalled as functions of experimental condition (congruent vs. disparate state), exemplar type (common vs. rare), and test type [free recall (FR) vs. category cuing (CC)]. whereas a change of pharmacological state between the study and test sessions of the experiment produced a modest but consistent impairment in the free recall of both common and rare category exemplars, no comparable deficits were apparent under conditions of category cuing. Similar interactions have been observed by Swanson, Eich, and Kinsbourne (Note 4), whose experiment focused on the state-dependent effects of methylphenidate (Ritalin) in hyperactive children, and by Weingartner (1978, Cases 49-52) in a study of eserineproduced SDR in normal adults. ${ }^{7}$ Thus, by manipulating the presence or absence of explicit list cues (viz., category names) in the cognitive environment of the remem. berer, it is possible to demonstrate both the occurrence and the erasure of state dependence within one and the same experiencing individual. The reader may recall that a similar conclusion emerged from the SDR/levels-of analysis experiment that was described earlier. In this study, retrieval of information about both deeply and shallowly analyzed words was found to be state dependent for marijuana under conditions of free recall but not for recognition memory. Taken together, then, the results of the "category cuing" and "levels" studies suggest that (1) the occurrence of SDR is limited to experimental situations, such as free recall, in which "invisible" cues may be assumed to guide retrieval, and (2) the deleterious effect of a state change on performance in a test of nominally noncued recall can be completely negated by probing memory with "observable" list or copy cues.

Additional evidence concerning the roles of invisible, list, and copy cues in the demonstration of state dependence is presented in Table 4. Data appearing in this table illustrate the relation between the outcome of a given case with respect to the occurrence of SDR, on the one hand, and the nature of the retrieval cuesinvisible, list, or copy-that are assumed to be available to the rememberer, on the other. A total of 50 cases are represented in the table; Cases $01,07,26,31,37$, 42 , and 43 in the compendium of SDR experiments (Table 1) have been omitted since the negative outcomes obtained in these 7 cases may be ascribed to the administration of ineffective drug doses (see the section titled "Dosage of psychoactive drug").

Table 4

Case Outcome as a Function of the Nature of the Retrieval Cues Available to the Remember

\begin{tabular}{|c|c|c|c|c|}
\hline \multirow{2}{*}{$\begin{array}{c}\text { Nature of } \\
\text { Cues }\end{array}$} & \multicolumn{2}{|c|}{ Case Outcome } & \multicolumn{2}{|c|}{ Cases } \\
\hline & + & - & + & - \\
\hline Invisible & 23 & 3 & $\begin{array}{l}03-06,09,12,14,16,18,20,21 \\
23,27,29,39-41,49,51,53-56\end{array}$ & $28,32,47$ \\
\hline List & 1 & 10 & 44 & $22,24,30,34,38,45,46,48,50,52$ \\
\hline Copy & 2 & 11 & 02,10 & $08,11,13,15,17,19,25,33,35,36,57$ \\
\hline
\end{tabular}

Note-Entries in the columns marked + and - are the numbers of cases in which evidence of SDR did and did not obtain, respectively. "Cases" refers to entries in Table 1. 
There are three points to be made with respect to the pattern of case outcomes depicted in Table 4. First, how likely or unlikely state-dependent effects are to be found depends in large measure on whether retrieval is tested in the presence or the absence of explicit reminders. With few exceptions, failures to demonstrate state dependence are confined to cases in which access to stored information was presumably mediated by "observable" list or copy cues, and successes, to cases in which retrieval must have been guided by "invisible" stimuli. As might be inferred on the basis of visual inspection of the data, statistical analysis reveals that the magnitude of this so-called cuing effect is impressive $\left[\chi^{2}(2)=28.95, \phi^{\prime}=.761\right]^{8}$

Second, when the nature of the retrieval cues available to the rememberer remains constant, the probability of demonstrating state dependence also remains constant across a broad spectrum of experimental conditions. Inspection of Table 4 (using information provided in Table 1 and in the section labeled "Format of the compendium and types of retrieval cues" as the basis for inspection) reveals that in situations in which access to stored information could only have been mediated by invisible retrieval cues, state-dependent effects have been found with anesthetics as well as with stimulants (e.g., Cases 03 and 04), with both deeply and shallowly analyzed words (Cases 14 and 16), and with target items reproduced under conditions of either free or nominally noncued serial recall (e.g., Cases 09 and 29). It may also be seen that in situations in which retrieval was tested in the presence of discretely identifiable list cues, rarely has SDR been observed, despite considerable variation, from one instance to the next, in the kind of drug administered (e.g., Cases 24 and 34), the composition of the cue-target pairs (e.g., Cases 38 and 46), and the type of cued recall task employed, that is, paired associate learning (e.g., Case 48) as opposed to category cuing (e.g., Case 50). Similar invariances may be discovered by comparing the methods and procedures used in cases that pertain to the operation of copy cues (e.g., Cases 15, 25, 35, and 57).

Finally, data appearing in Table 4 lend credibility to the claim that the unpredictability of human statedependent retrieval is more apparent than real. Inspection of the table discloses a total of 26 cases involving the nominally noncued free or serial recall of target items, tasks in which the level of recall performance may be assumed to be directly related to the effectiveness of invisible retrieval cues. Of these 26 cases, 23, or roughly $88 \%$, yielded reliable evidence of SDR. By any reasonable standard, this is high likelihood of success and is hardly the result one would expect of a genuinely unpredictable phenomenon. Thus, the "problem" of unpredictability stated at the outset of the paper turns out not to be a problem after all, but rather a natural consequence of neglect of the roles invisible and observable cues serve in the occurrence of human state dependence. Still, it remains to be explained why state-dependent effects should be more likely to emerge when recollection is at tempted in the absence of explicit reminders than in their presence. Speculations about the nature of the cognitive processes underlying the cuing effect in human state-dependent retrieval are considered in the next and concluding major part of the article.

\section{DISCUSSION}

\section{The "Message" of the Paper}

The purpose of this report has been to identify sources of the apparent unpredictability of human SDR. To this end, a substantial body of evidence has been examined concerning the roles of several, seemingly important experimental variables in the occurrence of SDR. Of the variables considered, one-the presence or absence of explicit retrieval cues in the cognitive environment of the rememberer-seems to matter most. More specifically, it has been shown that, whereas evidence of state dependence almost invariably obtains under conditions in which retrieval is tested in the absence of discretely identifiable list or copy cues, rarely is the phenomenon demonstrated when retrieval is tested in the presence of such "observable" reminders. It has also been shown that when the nature of the cues available to the rememberer is held constant, manipulations of variables, including the type of centrally acting drug administered, the composition of the to-be-remembered items, and the "level" of item analysis, generally have little influence on the likelihood of demonstrating SDR. Consequently, if there was but one "message" to be taken from the evidence and analyses presented thus far, it would be that human SDR is a cue-dependent phenomenon, that is, one whose occurrence critically depends on the exact nature of the retrieval information or cues that are available to the rememberer.

There are five senses in which this basic message may be of interest and significance to students of both memory in general and SDR in particular. First, given that state-dependent effects almost always obtain in experiments in which only invisible cues are available to the rememberer (and this, despite considerable variation, from one experiment to the next, in the drugs, stimulus materials, and tasks employed), it becomes increasingly difficult to cling to the belief that, in the words of Hilgard and Bower (1975, p. 547), evidence of SDR in man "rests on precarious grounds." There are, to be sure, many vexing problems to be resolved in the quest of an explanation of human state dependence, several of which will be considered below, but the purported 
unpredictability of the phenomenon need not be counted among them.

Second, investigators who seek to evaluate the capacity of a drug to elicit state-dependent effects in man would be well advised to design their experiments with a view to the finding that such effects are unlikely to occur when retrieval is prompted with explicit list or copy cues. This should be a particularly important consideration in experiments dealing with clinically significant drugs, such as the phenothiazines and tricyclic antidepressants, that have not previously been studied within the context of SDR; in such experiments, questions of state dependence may be of relevance both in the analysis of the underlying mechanisms of drug action and in the assessment of the therapeutic efficacy of the agent.

Third, there is reason to believe that the presence or absence of explicit retrieval cues is a key determinant not solely of the occurrence of human state dependence, but of infrahuman state dependence as well. The pertinent evidence comes from a recent study reported by Connelly, Connelly, and Phifer (1975) on the statedependent effects of chlordiazepoxide hydrochloride (Librium) on the performance of an escape-learning task (also see Connelly, Connelly, \& Epps, 1973). During the initial phase of this experiment, male hooded rats were trained to run to either the left or the right goalbox of a T maze. A black curtain was suspended at the entrance to each goalbox, and behind each curtain was a guillotine door. Throughout training, the door leading to the experimentally designated "correct" goalbox was left open, while the door to the incorrect box remained closed. The choice point separating the goalboxes was electrified, as was the area from which the animal began its run, so it behooved the subject to move from the starting gate to the correct goalbox as quickly as possible. Subjects were trained under either drug-present or drug-free conditions (States $\mathrm{D}$ and $\mathrm{N}$, respectively). Training continued until the animal could go the distance between the start- and goalboxes in less than $1 \mathrm{~min}$ on 18 out of 20 consecutive trials.

One day after the criterion of learning was reached, subjects were given 5 days of testing with five trials/day. On each test trial, the animal was again placed in the startbox, but now both guillotine doors were opened and no electric shocks were administered. Subjects were tested in the same drug state as original training on the even-numbered testing days and in the opposite state on odd-numbered days (e.g., D training; N-D-N-D-N testing).

Results of the test sessions yielded clear evidence of state dependence: When training and testing were completed in the same drug state (D or N), the animals almost invariably turned to the correct goalbox (i.e., the box to which they had been trained to run); however, when testing took place in the state opposite to that of original learning, the subjects responded in a random fashion, with left and right turns occurring equally often.
In addition to training and testing animals in the manner sketched above, Connelly et al. (1975) also ran a second group of subjects, the "tone" group. During the initial training of the second group, a $1-\mathrm{kHz}$ tone was sounded as soon as the animal was placed in the electrified startbox; in this manner, fear produced by the shock became classically conditioned to the auditory stimulus. During the 5 days of nonshock testing, the tone was reactivated every time the subject was returned to the startbox, regardless of whether testing ensued in the same state as training or in the alternate state. In all other respects, training and testing were identical to that received by the "no-tone" subjects, as described above.

Under conditions in which the tone was present at acquisition and at test, no evidence of state dependence was apparent. Irrespective of the similarity or dissimilarity of acquisition and test drug states, animals classically conditioned to the tone consistently turned in the direction established during original learning; as Connelly et al. (1975, p. 141) put it, "they remembered and performed what they had been trained to do." Thus it appears that by providing the rememberer-whether human or laboratory animal-with an appropriate, "observable" reminder-a tone, category name, copy cue, or whatever-the deleterious effect of a change of drug state can be effectively mitigated.

The fourth point of interest is revealed in the outcomes of three recent studies of context effects in human episodic memory. In the first of these studies (Godden \& Baddeley, 1975; also see Baddeley, 1976, pp. 74-75), experienced scuba divers studied a long list of common, unrelated words in one of two natural environments, underwater or on land, and were later tested for both free recall and recognition memory either in the same environment in which memorization occurred or in the alternate context. Results of the free recall test yielded unmistakable evidence of context-dependent retrieval: Whereas an average of 35\% of the target words were reproduced when testing took place in the original learning environment, the mean corresponding to the disparate context conditions of the experiment was only $24 \%$. In sharp contrast to these results, manipulations of study-test contexts were found to produce negligible effects on the probability of target word recognition (Baddeley, 1976, pp. 74-75). This pattern of experimental outcomes should strike the reader as familiar, for it is identical to the pattern observed in the "levels" study of marijuana-induced SDR that was examined earlier. Thus it looks as though the cuing effect is capable of manifesting itself not only at the level of the sea, but beneath it as well.

In a second relevant study (Weingartner, Note 5), unipolar depressive patients studied a list of conceptually categorized words the morning after a sleepless night and were subsequently tested for retrieval either in a comparable "affective" context of sleep deprivation or following a normal night's rest. Context dependence was evident under conditions of free recall, but it disappeared 
when category names were provided as retrieval cues, a finding that parallels results obtained in the "category cuing" study of the state-dependent properties of marijuana that was reviewed previously. Finally, Smith, Glenberg, and Bjork (1978) have reported a series of experiments involving systematic manipulations of the similarity between the rooms in which college students memorized and were later tested for the retention of common words. Their data show quite clearly that only when recollection is tested in the absence of discretely identifiable list or copy cues are substantial contextdependent effects likely to be in evidence (cf. Abernethy, 1940; Smith \& Guthrie, 1921).

Thus we have at hand three experiments, each requiring the services of different types of individuals, each involving different kinds of contextual manipulations, and each presumably undertaken with somewhat different hypotheses in mind. Yet a leitmotiv emerges from the collective data: Depending on the presence or absence of explicit retrieval cues in the cognitive environment of the rememberer, evidence of context-dependent retrieval is less or more likely to obtain. This, of course, is precisely the same theme that runs through the literature concerned with the context-dependent effects of centrally acting drugs. Hence it is apparent that the generality of the cuing effect extends not only across different species of subject (as revealed by the work of Connelly et al, 1975, described above), but also across different varieties of context.

Finally, and arguably most important, recognition of the cue-dependent nature of human SDR brings into bold relief questions for future research that otherwise might have been overlooked. How, for instance, is it possible that appropriate category-name cues completely negate the deleterious effect of a change of drug state upon retrieval performance, when surely cuing per se does not serve to reintroduce the original pharmacological context (Roediger, 1975)? Can the amnesic effect of state change be attenuated by the provision of cues in addition to those of a lexical or pictorial nature-fragrance cues, for example. And is there a basic difference, with respect to the importance of cuing conditions, between context effects elicited by drugs and those associated with, say, hypnotically induced mood states (Bower, Monteiro, \& Gilligan, 1978) or natural biological rhythms (Holloway, 1978), or is it the case that pharmacological and nonpharmacological manifestations of contextdependent retrieval differ solely at the level of empirical operations? But of the many questions one might want to ask about the cuing effect and its implications, perhaps the most obvious is: why does the effect occur? A tentative answer to this question is offered below.

\section{The Cuing Effect: Speculations, Assumptions, and Tentative Explanation}

We have seen that an important determinant of the phenomenon of SDR is the presence or absence of explicit cues as part of the retrieval test. Granted the existence of the cuing effect in human state dependence, how might we explain its occurrence?

One approach to this question is based on the principle of encoding specificity (Tulving, 1976, 1979; Tulving \& Thomson, 1973). According to this principle, "specific encoding operations performed on what is perceived determine what is stored, and what is stored determines what retrieval cues are effective in providing access to what is stored" (Tulving \& Thomson, 1973, p. 369). Thus, to take a simple example from a study described earlier, if "what is perceived" is the appearance of the target word DAISY in an experimental list, and if "what is stored" includes information about the class or category of objects to which the word commonly refers, then presentation of the category name Flowers will facilitate the recall of DAISY as the target word. The assumption here is that retrieval information contained in the cue will match or complement information stored in episodic memory about the target word event; hence, DAISY is more likely to be recalled in the presence of Flowers than in the absence of the category name cue.

If what is stored, the memory trace, also includes information about the particular pharmacological state in which DAISY was initially encoded, then that state too will serve as an effective retrieval cue. That is, reinstatement at output of the pharmacological context in which the target word was presented may be seen to provide the rememberer with an invisible cue for retrieval or with a source of such pharmacological cues. Hence, DAISY is more likely to be recalled in the presence of appropriate pharmacological cues (i.e., under congruent state experimental conditions) than in their absence (i.e., under disparate state conditions).

In the foregoing example, a situation is depicted in which recollection of the word event DAISY might be facilitated by the presentation of either of two kinds of retrieval cues: one "observable" in nature (the category name Flowers), the other "invisible" (the reinstated pharmacological context). The possibility that access to stored information about one and the same event might be gained through such qualitatively different retrieval stimuli suggests a simple yet plausible explanation for the cuing effect in human state dependence. Specifically, under conditions in which recall of the target word DAISY is tested in the absence of any effective, observable reminders such as Flowers, the subject will be forced to rely solely on invisible cues to guide retrieval. Given that the immediate drug state of the rememberer may serve as a source of these invisible stimuli, and on the unassailable assumption that pharmacological cues available in State A will have more information in common with events that were encoded in a similar State $A^{\prime}$ than those encountered in a dissimilar State B (cf. Tulving, 1976), then we may expect the probability of 
the recall of DAISY to vary as a direct function of the completeness of the reinstatement, at retrieval, of the original encoding state. Hence, retrieval of information about the target word event should appear to be drugstate dependent.

Alternatively, under conditions in which recall of DAISY as the target word is tested in the presence of an explicit reminder such as Flowers, the subject need not rely exclusively on invisible cues to mediate retrieval. Even though appropriate pharmacological cues may be unavailable to the rememberer (as presumably would be the case following a change of drug state), access to stored information about the word event nevertheless might be gained via the observable stimulus. Indeed, so long as appropriate retrieval information can be and is extracted from the cue Flowers under disparate as well as congruent states (cf. Tulving, 1976), we may expect the probability of the recall of DAISY to be relatively invariant with respect to the similarity (or dissimilarity) between encoding and retrieval states. Hence, retrieval of information about the target word event should not appear to be drug-state dependent. The pastiche of assumptions, speculations, and inferences sketched above thus strongly implies, and in a modest sense explains, what we now know to be an empirical fact: that other things being equal, state-dependent effects are more likely to be found when retrieval is tested in the absence of discretely identifiable reminders than in their presence.

Full implications of the proposed explanation of the cuing effect remain to be worked out and explored. As noted above, whether or not a to-be-remembered event such as DAISY is recalled in the presence of an explicit retrieval stimulus such as Flowers will be independent of the similarity between encoding and retrieval drug states provided that appropriate information can be and is extracted from the cue. It follows that if, for any reason, the information derived from the cue is not compatible with stored information about the target event, the mere presence of the cue as part of the memory test will diminish neither the extent to which the subject must rely on unseen pharmacological cues to effect retrieval nor, consequently, the likelihood with which retrieval will appear to be drug-state dependent. Thus, a promising approach to the study of human state dependence would be to investigate the conditions under which discretely identifiable retrieval cues fail to make contact with the memory traces of to-be-remembered events, for it will be under these very same conditions that state-dependent effects should manifest themselves despite the presence of observable reminders.

\section{The Cuing Effect and the Principle of Ceteris Paribus}

In search of sources of the apparent unpredictability of human SDR, we have examined evidence concerning several experimental variables that have been or might be thought to play key roles in the occurrence of the phenomenon. By now it is a familiar story to the reader that the variable of chief significance seems to be the presence or absence of discretely identifiable retrieval cues in the cognitive environment of the rememberer. It should be made clear, however, that the assertion about the critical role played by cuing conditions in the occurrence of SDR, like any other scientific hypothesis, must be accepted within the spirit of the principle of ceteris paribus: Evidence for one source of influence does not rule out the possibility of contributions from other sources (A. C. Petersen, 1979; Tulving, 1979). The observation that, in the main, failures to demonstrate state dependence are not attributable to the type of centrally acting agent administered, the quantity of drug dispensed, the nature of the items whose occurrence the subject is asked to remember, or the level at which the items are analyzed at input does not mitigate the relevance of the principle to our present concerns, for it could well be argued that these variables do not exhaust the list of potentially important factors. Indeed, it has been suggested that the likelihood of demonstrating state-dependent effects in man depends, among other things, on the degree of original learning (Cohen \& Rickles, 1974), the population from which the subject sample is drawn (Lisman, 1974; Weingartner \& Faillace, 1971), and the extent to which processing and utilization of serial order information is required in the performance of the memory task at hand (Eich, 1977; Hill et al., 1973; Stillman et al., 1974). The evidence on which these suggestions are based is, however, fragmentary, and for this reason it was not considered in the present report. Still, we would be wise to keep an open mind about such matters. Although there can be little doubt that the nature of the cuing conditions is an important factor in the occurrence of human SDR, other variables of equal, perhaps even greater, significance may exist, awaiting discovery.

\section{REFERENCE NOTES}

1. Storm, T., Caird, W. K., \& Korbin, E. The effects of alcohol on rote verbal learning and retention. Paper presented at the annual convention of the Canadian Psychological Association, Vancouver, British Columbia, April 1965.

2. Eich, J. E. Dissociation of memory: A state of the researchart report. Paper presented at the conference on alcohol and human memory, Laguna Beach, California, August 1976.

3. Eich, J. E., Stillman, R. C., Weingartner, H., Beardsley, H., \& Wyatt, R. J. Availability vs. accessibility of information in state-dependent memory. Paper presented at the annual convention of the American Psychological Association, New Orleans, Louisiana, August 1974.

4. Swanson, J. M., Eich, J. E., \& Kinsbourne, M. Stimulantrelated state-dependent retrieval in free recall. Paper presented at the annual meeting of the Psychonomic Society, San Antonio, Texas, November 1978.

5. Weingartner, H. Mood-state dissociation. Paper presented at the Asilomar workshop on the psychological effects of abusable drugs, Monterey, California, January 1978. 


\section{REFERENCES}

Abernethy, E. M. The effect of changed environmental conditions upon the results of college examinations. Journal of Psychology, 1940, 10, 293-301.

Adams, N., Castro, A. D., \& Clark, D. L. State-dependent learning with a general anesthetic (Isoflurane) in man. T. I. $-T$. Journal of Life Sciences, 1974, 4, 125-134.

Baddeley, A. D. The psychology of memory. New York: Basic Books, 1976

BAнRICK, H. P. Availability versus accessibility of retrieval cues in the retention of a categorized list. Journal of Experimental Psychology, 1971, 89, 117-125.

Battig, W. F., \& Montague, W. E. Category norms for verbal items in 56 categories: $A$ replication and extension of the Connecticut category norms. Journal of Experimental Psychology Monograph, 1969, 80(No. 3, Pt. 2).

Birnbaum, I. M., Parker, E. S., Hartley, J. T., \& Noble, E. P. Alcohol and memory: Retrieval processes. Journal of Verbal Learning and Verbal Behavior, 1978, 17, 325-336.

Bower, G. H., Monte iro, K. P., \& Gilligan, S. G. Emotional mood as a context for learning and recall. Journal of Verbal Learning and Verbal Behavior, 1978, 17, 573-585.

Bustamante, J. A., Jordán, A., Vila, M., González, A., \& Insua, A. State dependent learning in humans. Physiology \& Behavior, 1970, 5, 793-796.

Bustamante, J. A., Rosselló, A., Jordán, A., Pradere, E., \& Insua, A. Learning and drugs. Physiology \& Behavior, 1968 , $3,553-555$

Cohen, M. J., \& Rickles, W. H., JR. Performance on a verbal learning task by subjects of heavy past marihuana usage. Psychopharmacologia (Berlin), 1974, 37, 323-330.

Connelly, J. F., Connelty, J. M., \& Epps, J. O. Disruption of dissociated learning in a discrimination paradigm by emotionally-important stimuli. Psychopharmacologia (Berlin), 1973, 30, 275-282.

Connelly, J. F., Connelly, J. M., \& Phifer, R. Disruption of state-dependent learning (memory retrieval) by emotionallyimportant stimuli. Psychopharmacologia (Berlin), 1975, 41, 139-143.

Cowan, J. D. Implications of state dependent learning for drug abuse. Problems of Drug Dependence, 1976, 38, 888-921.

Craik, F. I. M., \& Tulving, E. Depth of processing and the retention of words in episodic memory. Journal of Experimental Psychology: General, 1975, 104, 268-294.

Crow, L. T., \& Ball, C. Alcohol state-dependency and autonomic reactivity. Psychophysiology, 1975, 12, 702-706.

Darley, C. F., Tinklenberg, J. R., Roth, W. T., \& Atrinson, R. C. The nature of storage deficits and state-dependent retrieval under marihuana. Psychopharmacologia (Berlin), 1974, 37, 139-149.

DeEse, J., \& Hulse, S. H. The psychology of learning (3rd ed.). New York: McGraw-Hill, 1967.

Deutsch, J. A., \& Roll, S. K. Alcohol and asymmetrical statedependency: A possible explanation. Behavioral Biology, 1973 8, 273-278.

DownEY, D. J. State-dependent learning with centrally and noncentrally active drugs. Bulletin of the Psychonomic Society, $1975,5,281-284$.

EICH, J. E. State-dependent retrieval of information in human episodic memory. In I. M. Birnbaum \& E. S. Parker (Eds.), Alcohol and human memory. Hillsdale, N.J: Erlbaum, 1977.

Eich, J. E., Weingartner, H., Stillman, R. C., \& Gillin, J. C. State-dependent accessibility of retrieval cues in the retention of a categorized list. Journal of Verbal Learning and Verbal Behavior, 1975, 14, 408-417.

Fisher, R. P., \& Craik, F. I. M. The interaction between encoding and retrieval operations in cued recall. Journal of
Experimental Psychology: Human Learning and Memory, 1977, 3, 701-711.

Flexser, A. J., \& Tulving, E. Retrieval independence in recognition and recall. Psychological Review, 1978, 85, 153-171.

Godden, D. R., \& Baddeley, A. D. Context-dependent memory in two natural environments: On land and underwater. British Journal of Psychology, 1975, 66, 325-332.

Goodman, L. S., \& Gilman, A. The pharmacological basis of therapeutics (5th ed.). New York: Macmillan, 1975.

Goodwin, D. W., Powell, B., Bremer, D., Hoine, H., \& STERN, J. Alcohol and recall: State dependent effects in man. Science, 1969, 163, 1358-1360.

HaYs, W. L. Statistics for psychologists (2nd ed.). New York: Holt, Rinehart, \& Winston, 1973.

HILGARD, E. R., \& BOWER, G. H. Theories of learning (4th ed.). Englewood Cliffs, N.J: Prentice-Hall, 1975.

Hill, S. Y., Schwin, R., Powell, B., \& Goodwin, D. W. State-dependent effects of marihuana on human memory. Nature, 1973, 243, 241.242.

Hinrichsen, J. J., Katahn, M., \& Levenson, R. W. Alcoholinduced state-dependent learning in non-alcoholics. Pharmacology, Biochemistry \& Behavior, 1974, 2, 293-296.

Holloway, F. A. State dependent retrieval based on time of day. In B. T. Ho, D. W. Richards III, \& D. L. Chute (Eds.), Drug discrimination and state dependent learning. New York: Academic Press, 1978.

Hurst, P. M., Radlow, R., Chubb, N. C., \& Bagley, S. K Effects of d-amphetamine on acquisition, persistence, and recall. American Journal of Psychology, 1969, 82, 307-319.

Hyde, T. S., \& JENKINS, J. J. Differential effects of incidental tasks on the organization of recall of a list of highly associated words. Journal of Experimental Psychology, 1969, 82, 472-481.

JoNES, B. M. Memory impairment on the ascending and descending limbs of the blood alcohol curve. Journal of Abnormal Psychology, 1973, 82, 24-32.

Ley, P., Jain, V. K., Swinson, R. P., Eaves, D., Bradshaw, P. W., Kincey, J. A., Crowder, R., \& Abriss, S. A. A state-dependent learning effect produced by amylobarbitone sodium. British Journal of Psychiatry, 1972, 120, 511-515.

LiLjequist, R., Linnoila, M., \& MatTila, M. J. State-dependent effect of diazepam on learning. British Journal of Pharmacology, 1977, 59, 518(P).

Lisman,.S. A. Alcoholic "blackout": State dependent learning? Archives of General Psychiatry, 1974, 30, 46-53.

McNemar, Q. At random: Sense and nonsense. American Psychologist, 1960, 15, 295-300.

Melton, A. W., JR. Editorial. Journal of Experimental Psychology, 1962, 64, 553-557.

Miller, M. E., Adesso, V. J., Fleming, J. P., Gino, A., \& LAuerman, R. Effects of alcohol on the storage and retrieval processes of heavy social drinkers. Journal of Experimental Psychology: Human Learning and Memory, 1978, 4, 246-255.

Moscovitch, M., \& Craik, F. I. M. Depth of processing, retrieval cues, and uniqueness of encoding as factors in recall. Journal of Verbal Learning and Verbal Behavior, 1976, 15 , 447-458.

Osbonn, A. G., Bunker, J. P., Cooper, L. F., Frank, G. S., \& Hilgard, E. R. Effects of thiopental sedation on learning and memory. Science, 1967, 157, 574-576.

Overton, D. A. State-dependent or "dissociated" learning produced with pentobarbital. Journal of Comparative and Physiological Psychology, 1964, 57, 3-12.

Overton, D. A. State-dependent learning produced by depressants and atropine-like drugs. Psychopharmacologia (Berlin), 1966, $10,6-31$.

Overton, D. A. Discriminative control of behavior by drug states. In T. Thompson \& R. Pickens (Eds.), Stimulus properties of drugs. New York: Appleton, 1971. 
Overton, D. A. State-dependent learning produced by alcohol and its relevance to alcoholism. In B. Kissen \& A. Begleiter (Eds.), The biology of alcoholism: Physiology and behavior (Vol. 2). New York: Plenum Press, 1972.

Overton, D. A. State-dependent learning produced by addicting drugs. In S. Fisher \& A. M. Freedman (Eds.), Opiate addiction: Origins and treatment. Washington, D.C: Winston, 1973.

Overton, D. A. Experimental methods for the study of statedependent learning. Federation Proceedings, 1974, 33, 1800-1813.

Parker, E. S., Birniaum, I. M., \& Noble, E. P. Alcohol and memory: Storage and state dependency. Journal of Verbal Learning and Verbal Behavior, 1976, 15, 691-702.

Petersen, A. C. Comments on Professor Goleman's article (published as a letter to the editor). Psychology Today, 1979, $12,7$.

Petersen, R. C. Retrieval failures in alcohol state-dependent learning. Psychopharmacology, 1977, 55, 141-146.

Powell, B. J., Goodwin, D. W., Janes, C. L., \& Hoine, H. State-dependent effects of alcohol on autonomic orienting responses. Psychonomic Science, 1971, 25, 305-306.

Rickles, W. H., JR., Cohen, M. J., Whitaker, C. A., \& McIntyre, K. E. Marihuana induced state-dependent verbal learning. Psychopharmacologia (Berlin), 1973, 30, 349-354.

Roediger, H. L., III. Current status of research on retrieval processes in memory. Polygraph, 1975, 4, 304-310.

Roffman, M., Marshall, P., Silverste in, A., Karkalas, J., Sмітн, N., \& Lal, H. Failure to demonstrate "amphetamine state" controlling learned behavior in humans. In J. M. Singh, L. Miller, \& H. Lal (Eds.), Drug addiction: Clinical and sociolegal aspects (Vol. 2). Mt. Kisco, N.Y: Futura, 1972.

SIEGEL, S. Nonparametric statistics for the behavioral sciences. New York: McGraw-Hill, 1956.

Smith, S., Glenberg, A. M., \& Bjork, R. A. Environmental context and human memory. Memory \& Cognition, 1978, 6, $342-353$.

Sмiтн, S., \& Guthrie, E. R. General psychology in terms of behavior. New York: Appleton, 1921.

Stillman, R. C., Weingartaer, H., Wyatt, R. J., Gillin, J. C., \& Eich, J. E. State-dependent (dissociative) effects of marihuana on human memory. Archives of General Psychiatry, $1974,31,81-85$.

Swanson, J. M., \& Kinsbourne, M. Stimulant-related statedependent learning in hyperactive children. Science, 1976, 192, 1354-1357.

Swanson, J. M., \& Kinsbourne, M. The $2 \times 2$ design reconsidered: Limitations imposed by the statistical model. In F. C. Colpaert \& J. A. Rosecrans (Eds.), Stimulus properties of drugs: Ten years of progress. Amsterdam: Elsevier/NorthHolland Biomedical Press, 1978.

TARTER, R. E. Dissociate effects of ethyl alcohol. Psychonomic Science, 1970, 20, 342-343.

Tulving, E. Episodic and semantic memory. In E. Tulving \& W. Donaldson (Eds.), Organization of memory. New York: Academic Press, 1972.

Tulving, E. Ecphoric processes in recall and recognition. In J. Brown (Ed.), Recall and recognition. London: Wiley, 1976.

Tulving, E. Relation between encoding specificity and levels of processing. In L. S. Cermak \& F. I. M. Craik (Eds.), Levels of processing and human memory. Hillsdale, N.J: Erlbaum, 1979.

Tulving, E., \& Bowen, G. H. The logic of memory representations. In G. H. Bower (Ed.), The psychology of learning and motivation (Vol. 8). New York: Academic Press, 1974.

Tulving, E., \& Thomson, D. M. Encoding specificity and retrieval processes in episodic memory. Psychological Review, 1973, 80, 353-373.

Tulving, E., \& Watkins, M. J. Structure of memory traces. Psychological Review, 1975, 82, 261-275.

Weingartne R, H. Human state dependent learning. In B. T. Ho,
D. W. Richards III, \& D. L. Chute (Eds.), Drug discrimination and state dependent learning. New York: Academic Press, 1978. Weingartner, H., Adefris, W., Eich, J. E., \& Murphy, D. L. Encoding-imagery specificity in alcohol state-dependent learning. Journal of Experimental Psychology: Human Learning and Memory, 1976, 2, 83-87.

Weingartner, H., Eich, J. E., \& Allen, R. Alcohol state dependent associative processes. Proceedings of the American Psychological Association, 1973, 8, 1009-1010.

WeingartneR, H., \& Faillace, L. A. Alcohol state-dependent learning in man. Journal of Nervous and Mental Disease, $1971,153,395-406$.

Weingartner, H., Miller, H., \& Murphy, D. L. Mood-statedependent retrieval of verbal associations. Journal of Abnormal Psychology, 1977, 86, 276-284.

WiCKELGREN, W. A. Alcoholic intoxication and memory storage dynamics. Memory \& Cognition, 1975, 3, 385-389.

Wood, G. Category names as cues for the recall of category instances. Psychonomic Science, 1967, 9, 323-324.

\section{NOTES}

1. At the level of analytical operations, test-session data generated within the context of the 2 by 2 experimental design are typically submitted to a two-factor (study state vs. test state) analysis of variance. Essentially, this analysis tests for the main effect of drug on the formation and retention of target memory traces (the study-state factor), the main effect of drug on the utilization of target traces (the test-state factor), and the interactive or state-dependent effect of the agent (the interaction between study and test states). If the analysis of test-session data reveals a statistically reliable interaction (reliability is here defined in terms of alpha values less than 5\%; cf. Footnote 3 ), and if the data conform to the "crossover" pattern alluded to in the text above, the occurrence of state dependence is indicated (cf. Swanson \& Kinsbourne, 1978).

An alternative method for the analysis of 2 by 2 data has been employed by Weingartner and his associates (specifically, Cases $53-56$ in Table 1). The tactic here is to enter test-session data into a one-factor analysis of variance, with the four experimental conditions of the 2 by 2 design treated as levels of a single variable. If the "conditions" factor is revealed to be statistically significant, supplemental analyses are carried out with a view to identifying the locus of the reliable effect. In terms of statistical propriety, the one-factor method suffers in comparison with the two-factor analysis sketched above, in which the presence of state dependence is inferred partly on the basis of a significant interaction between study and test states. Nevertheless, the results reported by Weingartner and his colleagues are interpretable and do appear relevant to the issues of concern in the present paper.

Finally, it should be noted that although most of the material appearing in the compendium of SDR experiments (Table 1) is excerpted from studies involving the 2 by 2 design, alternative experimental configurations are represented in the compendium by Cases $01-06,33-38$, and 57 . Readers should consult the pertinent publications, cited in the compendium, for specific information concerning the experimental and analytical procedures followed in these cases. An alternative design was also employed in a previously unpublished study (Eich, Note 2, Cases 13-16 in Table 1); this study is examined in detail later in the present paper.

2. No distinction is posited in the present article between symmetric and asymmetric manifestations of SDR. In its broadest sense, asymmetric state dependence refers to the finding that information about the items or events to be remembered "transfers" less completely in the direction of drug-present to drugabsent states (experimental Condition DN) than in the reverse direction (Condition ND). Symmetric state dependence, in 
contrast, is defined by the observation of equally impaired transfer of information under both disparate state treatments. As has been pointed out by several methodologists (Deutsch \& Roll, 1973; Overton, 1974; Swanson \& Kinsbourne, 1978), the 2 by 2 design provides too little information to allow one to determine whether asymmetric state dependence is a genuine phenomenon, or whether apparent asymmetries result from the confluence of various "simple" drug effects, such as an impairment of encoding in combination with facilitation of retrieval. (This point also applies to experimental designs other than the 2 by 2 , including those represented by Cases $01-06$, $33-38$, and 57 in Table 1). Still, the 2 by 2 design, in addition to the alternative configurations entailed in the cases cited above, does appear suitable for the purpose of substantiating the occurrence of an "overall" state-dependent effect (Swanson \& Kinsbourne, 1978), and it is the presence or absence of such an effect that is of principal concern in this paper.

3. Several experiments that claim to focus on the state dependent effects of psychoactive drugs in normal adults are not cited in the compendium. In the case of Hinrichsen et al (1974), whose study addressed the state-dependent effects of alcohol upon paired associate learning, the $F$ value for the interaction between study and test states was significant at the $7 \%$ level. Since this value does not meet the criterion for statistical reliability adopted in the present paper (see Footnote 1) the outcome of the experiment in question might legitimately be classified as negative and so entered in the compendium However, the fact that the significance value associated with the critical interaction is so near the adopted criterion suggests that a technically reliable state-dependent effect might have obtained had Hinrichsen et al. tested a few more subjects or by some other means increased the statistical power of their experiment. (In this regard, it deserves notice that in every negativeoutcome case included in the compendium, statistical tests for the occurrence of state dependence yielded unquestionably nonsignificant results, with alpha values typically greater than $25 \%$ ). In view of the uncertain nature of its outcome, the Hinrichsen et al. experiment is excluded from consideration.

In three additional studies involving alcohol (Birnbaum, Parker, Hartley, \& Noble, 1978; Jones, 1973; Miller et al., 1978, Experiment 1), the experimental designs employed prohibit one from drawing any firm conclusions about the presence or absence of state-dependent effects.

In yet another study concerning alcohol (Cowan, 1976) interpretation of results pertaining to the recollection of repeatedly presented target items is clouded by the finding of inexplicably large differences in the degree of initial learning attained by subjects assigned to the DD and DN conditions of the experiment. (Cases 08 and 09 in Table 1 of the present paper refer to Cowan's results for once-presented targets.)

The sixth and final omission is the study of the statedependent properties of diazepam (Valium) reported by Liljequist, Linnoila, and Mattila (1977). Unfortunately, the methods and procedures followed in this experiment are not described in sufficient detail to permit an attempt at replication, and it is for this reason that the study is excluded from consideration.

4. Calculation of the expected number of cases works as follows: Of the 57 cases appearing in the compendium of SDR experiments (Table 1), 19 , or $33.3 \%$, involve the administration of marijuana. If the seven cases of ineffective dosing were distributed randomly among the four classes of psychoactive drugs specified in Table 2 , then 2.33 (33.3\% of 7 ) would pertain to marijuana. Rounded to the nearest integer, the expected number of cases of ineffective dosing with marijuana would thus be 2 , which is only 1 greater than the observed number (see text). Based on similar computations, the numbers of cases of ineffective dosing anticipated for the anesthetic, anticholinesterase, and stimulant classes are 4,0 , and 1 , respectively.

5. An alternative explanation for the finding of greater recall under Condition DD, relative to Condition DN, is that test performance may have been facilitated by the administration of marijuana. To the best of my knowledge, such a facilitative effect has never been demonstrated, at least within the context of the dosage of drug administered and the nature of the memory task employed in the present study. Thus, the superiority of Condition DD probably reflects the beneficial effect of preserving the pharmacological state of original learning, rather than a drug-engendered facilitation of test performance.

6 . It is conceivable that the failure to demonstrate statedependent recognition may be attributable to the administration of an ineffective dose of marijuana, that is, a dose too low to elicit a reliable main effect on either or both acquisition and retention (see the section titled "Dosage of psychoactive drug"). To check this possibility, a separate group of eight subjects both studied and were tested while sober (i.e., the congruent state Condition NN); in all other respects these subjects were treated in exactly the same fashion as participants in Conditions DD and DN. Whereas subjects assigned to Condition DD correctly recognized, on the average, .89 and .78 of the deeply and shallowly analyzed words, respectively, the corresponding mean proportions generated by NN subjects were .95 and .92 . Differences between the two conditions were reliable $[F(1,12)=7.33, \mathrm{MSe}=.009]$, which at once suggests the presence of a deleterious main effect of marijuana on recognition and disconfirms the possibility of ineffective dosing.

7. In describing his study of the state-dependent effects of eserine (physostigmine) upon the free and cued recall of conceptually categorized words, Weingartner (1978, Cases $49-52$ in Table 1) does not distinguish between common and rare category exemplars. In point of fact, however, Weingartner used the same categorized lists that were employed in the study of marijuanaproduced SDR reported by Eich et al. (1975, Cases 21-24; also see Figure 2). Doctor Weingartner has kindly provided me the complete results of the eserine study, and their pattern with respect to the free and cued recall of common and rare category instances appears very similar to the configuration of results obtained with marijuana.

8. Addition of the seven instances of ineffective dosing to the analysis of the relation between cuing conditions and case outcome does not diminish the robustness of the cuing effect. Indeed, the inclusion of the seven negative outcomes [five pertaining to list cues (Cases 07, 31, 37, 42, and 43) and two to copy cues (Cases 01 and 26)] slightly increases the magnitude of the cuing effect $\left[x^{2}(2)=35.53, \phi^{\prime}=.790\right]$. One final point: early in the paper, six seldom used tasks (representing 12 cases) were excluded from indepth analysis. These cases are difficult to classify with respect to the presence or absence of observable cues. However, even if it is assumed that all of these cases contradict the cuing hypothesis (an assumption which, though certainly wrong, is maximally conservative), the relation between cuing conditions and case outcome remains highly significant $\left[\chi^{2}(1)=15.70, \phi=.477\right]$.

(Received for publication August 23, 1979; revision accepted December $14,1979$. 